\title{
Endothelial nitric oxide synthase mediates the cerebrovascular effects of erythropoietin in traumatic brain injury
}

\section{Jovany Cruz Navarro ${ }^{1}$, Shibu Pillai ${ }^{1}$, Lucido L. Ponce ${ }^{1}$, Mai Van ${ }^{1}$, Jerry Clay Goodman ${ }^{2,3}$ * and Claudia S. Robertson ${ }^{1}$}

${ }^{1}$ Department of Neurosurgery, Baylor College of Medicine, Houston, TX, USA

${ }^{2}$ Department of Pathology and Immunology, Baylor College of Medicine, Houston, TX, USA

${ }^{3}$ Department of Neurology, Baylor College of Medicine, Houston, TX, USA

\section{Edited by:}

Pietro Ghezzi, Brighton and Sussex Medical School, UK

\section{Reviewed by:}

Barbara Viviani, University of Milan, Italy

Kursad Genc, Dokuz Eylül University, Turkey

\section{*Correspondence}

Jerry Clay Goodman, Department of Pathology and Immunology, Baylor

College of Medicine MS: BCM315,

One Baylor Plaza, Houston, TX 77030 ,

USA

e-mail:jgoodman@bcm.edu
Background: Erythropoietin (Epo) improves post-traumatic cerebral blood flow (CBF), pressure autoregulation, and vascular reactivity to L-arginine. This study examines the dependence of these cerebral hemodynamic effects of Epo on nitric oxide generated by endothelial nitric oxide synthase (eNOS).

Methods: Using laser Doppler flow imaging, CBF was monitored in wild-type (WT) and eNOS-deficient mice undergoing controlled cortical impact followed by administration of Epo $(5000 \mathrm{U} / \mathrm{kg})$ or normal saline.

Results: Cerebral blood flow decreased in all groups post-injury with the greatest reductions occurring at the impact site. Epo administration resulted in significantly higher CBF in the peri-contusional sites in the WT mice $[70.2 \pm 3.35 \%$ in Epo-treated compared to $53 \pm 3.3 \%$ of baseline in saline-treated mice $(p<0.0001)]$, but no effect was seen in the eNOS-deficient mice. No CBF differences were found the core impact site where CBF dropped to $20-25 \%$ of baseline in all groups.

Conclusion: These differences between eNOS-deficient and WT mice indicate that the Epo mediated improvement in CBF in traumatic brain injury is eNOS dependent.

Keywords: erythropoietin, traumatic brain injury, nitric oxide, nitric oxide synthase, neuroprotection, cerebral blood flow

\section{INTRODUCTION}

Traumatic brain injury (TBI) remains a major public health problem in the United States. Each year, an estimated 1.7 million people sustain some kind of TBI (1). More than 50,000 people die, and a larger number of head injured patients suffer permanent disability. Despite many promising experimental neuroprotection experiments, there is presently no effective treatment that promotes functional recovery in clinical TBI (2).

A substantial body of evidence has shown that erythropoietin (Epo) has extra-erythropoietic activities including neural protective effects against a wide variety of acute experimental insults, including spinal cord ischemia and trauma $(3,4)$, cerebral ischemia (5), bilateral carotid occlusion (6), retinal ischemia caused by uncontrolled intracranial pressure (7), subarachnoid hemorrhage (8), and subdural hematoma (9). Administration of Epo and Epo-analogs in experimental models of TBI leads to functional, morphological, and cognitive recovery that has been attributed to a several cytoprotective mechanisms including inhibition of apoptosis, anti-oxidant and anti-inflammatory actions, improved tissue oxygenation due to vascular effects, and stimulation of neurogenesis and angiogenesis (10-21). In the present study, we examined the effect of Epo on cerebral blood flow (CBF) and the dependence of this effect on endothelial nitric oxide synthase (eNOS) following controlled cortical impact (CCI).

\section{BACKGROUND}

Erythropoietin is a $34-\mathrm{kDa}$ glycoprotein consisting of 165 amino acids residues, synthesized mainly by the fetal liver and adult kidney that is responsible for the proliferation, survival, and differentiation of erythroid progenitor cells $(22,23)$. Epo and erythropoietin receptor (EpoR) expression in the neonatal and adult brain are up-regulated during tissue hypoxia through an oxygen-sensing pathway mediated by hypoxia-inducible factors $(24,25)$. Epo acts by binding to a transmembrane receptor (EpoR) that belongs to the type I cytokine family, causing dimerization of the receptor, activating Janus-tyrosine-kinase-2 (JAK-2) that leads to several downstream signaling pathways involved in the hematopoietic and extra-hematopoietic effects of Epo $(23,26,27)$.

The mechanism of Epo neuroprotection is not entirely clear, and several pathways may be involved, including cerebrovascular effects through alterations in nitric oxide (NO) production by eNOS. In ischemia models, this neuroprotection may be mediated by hypoxia-inducible factor 1 (HIF-1) activating its target genes Epo, EpoR, and vascular endothelial growth factor (VEGF) (28-30). Alternatively, it has been suggested that Epo acts indirectly on endothelial cells via activation of the VEGF receptor system, which is the most important specific regulator of endothelial growth and a major angiogenesis factor. In vitro studies, suggest that Epo is a promising candidate in the treatment of 
cerebral aneurysms by increasing the expression of eNOS and VEGF (31). Epo administration to coronary artery endothelial cells up-regulates eNOS activity leading to enhance NO production (32). In an isolated rat heart ischemia-reperfusion model, pretreatment with Epo provides cardioprotection that is dependent on NO (33). NO also has an important neuroprotectant role in TBI. In rodent models of TBI, administration of $\mathrm{L}$-arginine increases NO levels in cerebral microdialyzate, restores CBF to near pre-injury levels and reduces the resulting contusion volume (34). Pre-injury administration of Epo in an experimental TBI model in rats treated with $\mathrm{L}$-arginine results in a significant CBF recovery, likely through a mechanism involving eNOS activity (18). In experimental intracerebral hemorrhage, Epo reduces inflammation around the hematoma and activates eNOS possibly leading to improved perfusion (35). When diffuse axonal injury is coupled with hypoxia, Epo administration results in improved motor and cognitive performance, improved neuritic sprouting, and less corpus callosum thinning (36).

The purpose of this study was to evaluate the role of eNOS in the vascular effects of Epo after CCI in wild type (WT) compared to eNOS knock-out mice. Our hypothesis was that Epo mediated effects on cerebrovascular physiology are eNOS dependent.

\section{MATERIALS AND METHODS}

This protocol was approved by the institutional animal protocol review committee, using guidelines for humane care and use of animals that were developed for the National Institutes of Health (NIH).

\section{CEREBRAL BLOOD FLOW EXPERIMENTS}

A total of 56 adult male WT eNOS+/+ mice (C57BL/6J, $n=28)$ and homozygous eNOS-deficient mice (B6129P2-Nos tm I Unc/J with a C57BL/6 genetic background, $n=28$; Jackson Laboratories, Bar Harbor, ME) were used to study the CBF response after Epo administration during the first $2 \mathrm{~h}$ of monitoring after experimental TBI. eNOS-deficient animals used in this experiment were the offspring of mating between heterozygous eNOS-deficient mice. The eNOS-deficient mice were produced using $1.2 \mathrm{~kb}$ neomycin cassette inserted into eNOS replacing 129 base pairs of exon 12 of the gene, disrupting the calmodulin binding site of the eNOS and introducing a premature stop codon in the transcripts. Disruption of the eNOS gene was confirmed by PCR. eNOS protein in cerebral cortex determined by western blotting was $40 \%$ that seen in WT animals.

eNOS-deficient and WT mice (14 mice per group) were randomly treated with Epo $(5000 \mathrm{U} / \mathrm{kg})$ or $0.5 \mathrm{ml}$ of normal saline (NS) administered intra-peritoneally (IP) $5 \mathrm{~min}$ after the controlled cortical injury. The different experimental groups included the following:

eNOS $+/-[\mathrm{NS}]=$ eNOS-deficient mice treated with NS eNOS $+/-[$ Epo $]=$ eNOS-deficient mice treated with Epo WT- $[\mathrm{NS}]=$ Wild-type mice treated with NS WT- $[$ Epo $]=$ Wild-type mice treated with Epo

The mice were anesthetized with 5\% isoflurane in $100 \%$ oxygen in a vented anesthesia chamber and maintained on
$2 \%$ isoflurane for the duration of the experiment using a volume-controlled ventilator (Hugo Sachs Elektronik-Harvard Apparatus, March-Hugstetten, Germany) adjusted to obtain and end-tidal $\mathrm{CO} 2$ level [EtCO2] between 35 and $40 \mathrm{~mm} \mathrm{Hg}$ monitored with microcapnography (Columbus Instruments, Columbus, OH, USA). Rectal temperature was maintained between 36 and $37^{\circ} \mathrm{C}$ using a heat pad and a rectal thermistor. Blood pressure was monitored via femoral artery cannulation.

Baseline mean arterial pressure (MAP) and CBF were obtained 15 min prior to the cortical impact and thereafter, MAP was monitored at 30-s intervals. CBF was measured immediately after Epo or NS injection at $5 \mathrm{~min}$ after CCI and then at 30,60, 90, and $120 \mathrm{~min}$ post-injury using a non-invasive laser Doppler flow (LDF) scanner (PIM3 System, Perimed AB Stockholm, Sweden). Periscan PIM3 measures the total microcirculatory blood perfusion including the perfusion in capillaries, arterioles, venules, and shunting vessels. Measurements from this instrument are expressed as arbitrary perfusion units (PU). To enable comparison of results, perfusion changes were expressed as percentage of baseline measurements. The LDF device was positioned $15 \mathrm{~cm}$ above the head, and PUs were measured in regions of interest (ROIs) ipsi- and contra-lateral to the injury. The ROIs consisted of the site of the impact, cerebral cortex adjacent to the impact site (peri-contusional), and the contra-lateral cerebral hemisphere.

Controlled cortical impact injury was produced as previously described (34). In brief, after craniectomy and dural exposure, the $3 \mathrm{~mm}$ diameter impactor tip was positioned perpendicular to the exposed surface of the brain at an angle of $45^{\circ}$ to the vertical. CCI $(3 \mathrm{~m} / \mathrm{s}, 1.5 \mathrm{~mm}$ deformation, $100 \mathrm{~ms}$ of duration) was performed using a voltage driven impactor (Benchmark Stereotaxic Impactor, myNeuroLab, St Louis, MO, USA).

\section{STATISTICAL ANALYSIS}

Outcome assessments that were repeated over time such as CBF were estimated using a mixed modeling procedure for analysis of variance to estimate changes in means of variables between groups (SAS Software System). MAP was analyzed using repeated measures two-way analysis of variance (RM ANOVA).

\section{RESULTS}

\section{MEAN ARTERIAL PRESSURE}

Figure 1 summarizes the changes in blood pressure that occurred following CCI. WT mice showed an initial MAP of $76.75 \pm 1.4 \mathrm{~mm} \mathrm{Hg}$ compared to $97.17+0.39 \mathrm{~mm} \mathrm{Hg}$ in the eNOS-deficient animals $(p<0.05)$. eNOS-deficient mice started from a higher baseline blood pressure that remained consistently higher throughout the experiment because of tonically reduced vasodilatation, but these animals had a greater relative drop (15\%) in MAP from baseline at the end of the $2 \mathrm{~h}$ monitoring period. Following treatment, WT animals had MAP measurements that remained closer to baseline values than the eNOS-deficient animals (genotype effect, $p<0.001$; time effect, $p<0.001$; time $\times$ genotype interaction, $p<0.001)$. At the end of the monitoring period, MAP averaged $86.35 \pm 4.48$ and $82.42 \pm 3.42 \mathrm{~mm} \mathrm{Hg}$ in the Epo/Saline eNOS deficient treated groups, respectively; compared to $73.35+1.83$ 


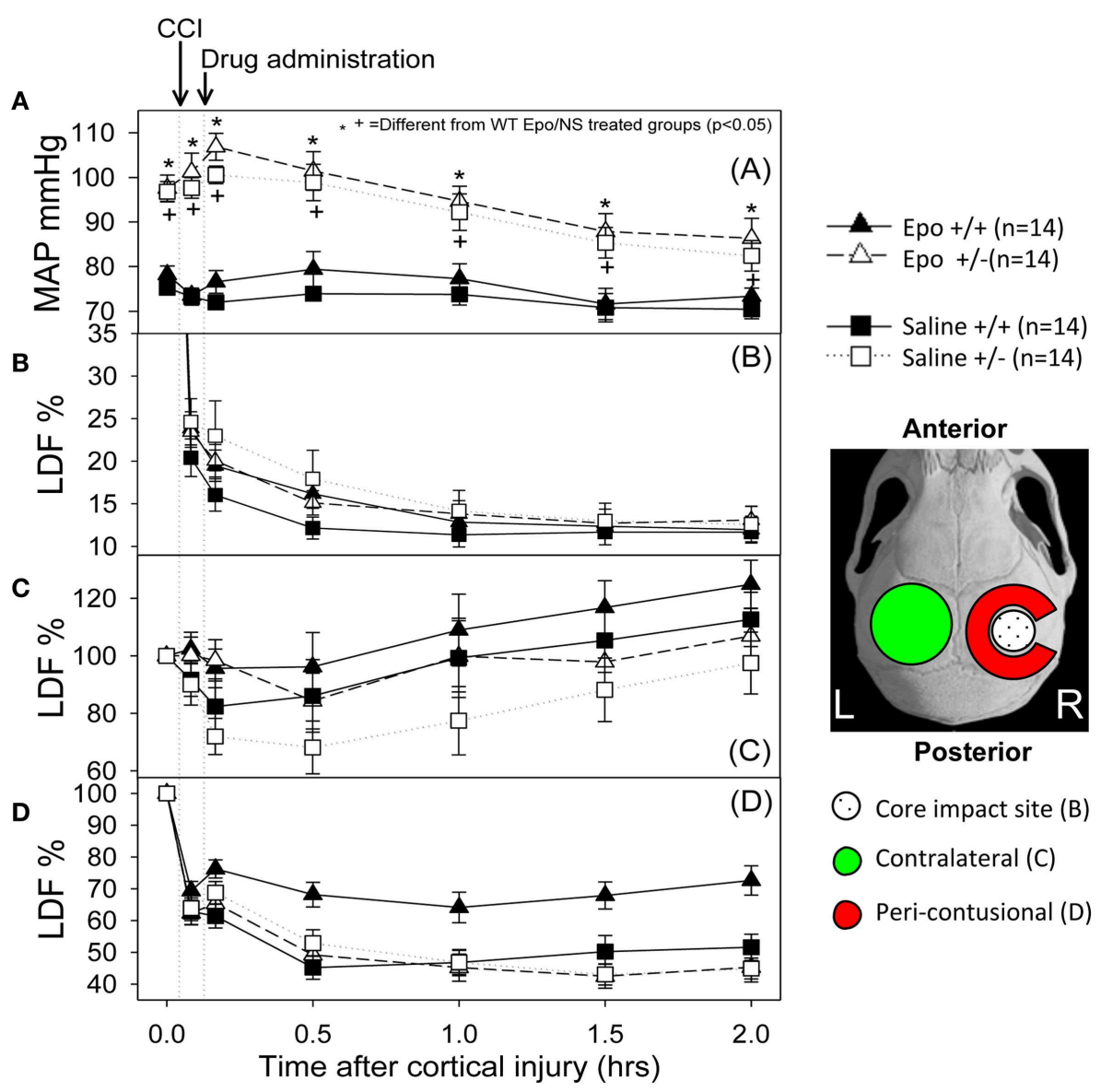

FIGURE 1 | Hemodynamic response to the controlled cortical impact (first arrow) followed by administration of the assigned treatment (second arrow). (A) Mean arterial pressure (MAP) changes during the experiment. The animals that were deficient in eNOS had a higher pre-injury MAP and had a greater drop in MAP after injury than the wild-type animals. When the group $\times$ time interaction was significant, symbols indicate which treatments were significantly different among the treatments' groups by the
Holm-Sidak post hoc test. (B-D) Cerebral blood flow response measured by laser Doppler in the core (B), contra-lateral (C) and peri-contusional (D) cerebral cortex. The core had a severe persistent drop in CBF regardless of the animal genotype or treatment group. The contra-lateral cortex showed a small to no decline followed by increased perfusion in all groups. In the peri-contusional regions, Epo treatment effect was seen in the WT animals but not in the eNOS-deficient animals ( $N=14$ per group). and $70.42 \pm 2.09 \mathrm{~mm} \mathrm{Hg}$ in the Epo/Saline WT treated animals, respectively $(p<0.05$, Holm-Sidak test).

\section{CEREBRAL HEMODYNAMICS}

Following cortical injury, CBF decreased in all treatment groups, with the greatest reductions occurring at the core impact site with less reduction in the peri-contusional cortex and least in the contra-lateral cortex. CBF fell in the impact site from $100 \%$ to a low value between 10 and $15 \%$ in all treatment groups by $2 \mathrm{~h}$ after cortical injury. No significant blood flow differences were found over time or by genotype at the core impact site $(p>0.05)$ (Figure 1B). Although not significant, a trend for better CBF recovery contralateral to the injury was observed over time favoring the WT animals (Figure 1C). Significant genotype and treatment differences in $\mathrm{CBF}$ were found only in the peri-contusional sites. Reduction in CBF values in the peri-contusional sites was similar between treatment groups immediately after cortical injury. Subsequently, peri-contusional CBF declined to $50 \%$ of baseline in the saline-treated animals and the Epo-treated eNOS-deficient animals, but Epo administration resulted in significantly higher $\mathrm{CBF}$ recovery in the peri-contusional region in the WT mice $(70 \pm 3.3 \%$ in Epo-treated groups compared to $53 \pm 3.35 \%$ in saline-treated mice; $p<0.05$ ) (Figure 1D). The results of the statistical analyses are summarized in Table 1 . In the peri-contusional (penumbral) area, there is a significant treatment effect and genotype effect but the interaction indicates that each depends on the other. There is also a significant change over time that depends on the genotype. There is no effect of Epo in the eNOS \pm genotype but the Epo effect is significantly greater in the eNOS WT genotype. These differences are most notable between pre-injury and pre-injection and the time points 30,60, 90, and $120 \mathrm{~min}$ after injury.

\section{DISCUSSION}

Cerebral pressure autoregulation is the intrinsic ability to maintain constant $\mathrm{CBF}$ over a range of blood pressures, and metabolic 
Table 1 | Multi-level statistical model for the cerebral blood flow (CBF) data comparing the EPO-treated and the saline-treated groups in the two genotypes of mice.

\begin{tabular}{|c|c|c|c|c|c|c|c|c|c|c|c|c|}
\hline Effect & \multicolumn{4}{|c|}{ Core } & \multicolumn{4}{|c|}{ Peri-contusional } & \multicolumn{4}{|c|}{ Contra-lateral } \\
\hline Treatment & 1 & 52 & 0.7 & 0.4056 & 1 & 52 & 5.29 & 0.0255 & 1 & 52 & 2.77 & 0.1023 \\
\hline Genotype & 1 & 52 & 0.92 & 0.3418 & 1 & 52 & 7.35 & 0.0091 & 1 & 52 & 2.13 & 0.1508 \\
\hline Treatment* genotype & 1 & 52 & 0.65 & 0.4248 & 1 & 52 & 8.00 & 0.0066 & 1 & 52 & 0.08 & 0.7832 \\
\hline Time* treatment & 5 & 260 & 0.19 & 0.9652 & 5 & 260 & 1.09 & 0.3684 & 5 & 260 & 0.39 & 0.8548 \\
\hline Time*genotype & 5 & 260 & 0.99 & 0.4221 & 5 & 260 & 6.91 & $<0.0001$ & 5 & 260 & 1.32 & 0.2572 \\
\hline Time ${ }^{*}$ treatment ${ }^{*}$ genotype & 5 & 260 & 1.50 & 0.189 & 5 & 260 & 1.11 & 0.357 & 5 & 260 & 0.35 & 0.8804 \\
\hline
\end{tabular}

NDF, numerator degrees of freedom; DDF, denominator degrees of freedom.

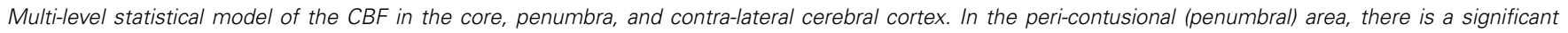

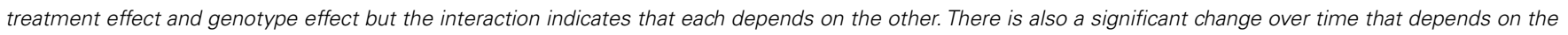

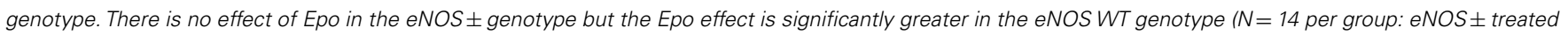
with normal saline, eNOS \pm treated with Epo, eNOS treated with normal saline, and eNOS treated with Epo).

cerebral autoregulation is the ability of the brain to locally adjust $\mathrm{CBF}$ to meet cerebral metabolic requirements (37). Cerebral pressure autoregulation is disrupted in TBI and this may be due to dysfunction of endothelial NO production.

Nitric oxide plays an important role in a number of general physiological processes of the brain, such as the maintenance of basal vasomotor tone, selective neuroprotection, synaptogenesis, and synaptic plasticity; therefore, NO has multiple and complex roles in the pathophysiology of TBI. NO is a cell membranepermeable free radical synthesized from the amino acid $\mathrm{L}$-arginine by the enzyme NOS (38). In TBI, both excess and deficiency of NO can potentially result in detrimental effects. Depletion of NO produced by eNOS may result in inadequate cerebral perfusion, whereas excess NO produced by nNOS and iNOS could potentially lead to neurotoxicity and cellular injury. Such changes in cerebral NO metabolism have been implicated in the pathophysiological changes occurring after TBI. Triphasic (high-low-high) changes in cerebral concentration of NO after TBI have been described in experimental and clinical studies. A brief rise in NO concentration lasting seconds to minutes immediately after injury in experimental models is followed by a protracted decrease $(0.5-$ $6 \mathrm{~h}$ ) in NO concentrations that may partly account for the low CBF observed during this period after injury. This is followed by a late phase $(>6 \mathrm{~h})$ in which an elevation in cerebral NO is associated with a return to normal or even elevated levels of CBF. Increased expression of iNOS protein in cerebrovascular smooth muscles has been observed during this phase, and CSF levels of NO have been reported to peak between 20 and $42 \mathrm{~h}$ after TBI (39). During the early phase, a period of relative deficiency in NO and a low level of $\mathrm{CBF}$, the administration of $\mathrm{L}$-arginine has been shown to improve $\mathrm{CBF}$ and neurological outcome in models of TBI (34). Administration of $\mathrm{L}$-arginine in patients after severe TBI induced an increase in internal carotid artery flow volume, which was larger at $48 \mathrm{~h}$ than at $12 \mathrm{~h}$, and tended to be larger in the less injured hemisphere at both time periods, suggesting that dysfunction of cerebrovascular endothelium plays a role in the reduced CBF observed after TBI
(40). Some of the variability in patient outcome that occurs following severe TBI may result from eNOS polymorphisms (41). During the late peak in NO after TBI due to the activity of iNOS, the inhibition of iNOS has been neuroprotective in experimental models of TBI (42-44). L-Arginine administration may or may not result in an increase of CBF after CCI depending upon whether or not the mice had been hemorrhaged (45). It is well documented that $\mathrm{CBF}$ and cerebral autoregulation are heterogeneous after TBI and tend to be reduced in the immediate vicinity of a contusion (46).

Our experimental model focuses on the early phase after CCI and previous studies have shown a lower plasma and microdialysate NO concentration in the eNOS-deficient mice compared to WT mice. Our study also showed a sustained decrease in post-traumatic CBF in eNOS-deficient mice compared to WT mice. eNOS-deficient mice had significant lower CBF in pericontusional areas of the brain in spite of maintaining higher MAP compared to WT mice. Moreover, earlier studies have demonstrated that eNOS-deficient mice have higher MAP than do WT mice but comparable CBF (47), these finding have been confirmed in the present study. It has also been shown that cortical blood flow, measured by laser Doppler, is reduced by about $70 \%$ from baseline in eNOS-deficient mice and by about $50 \%$ in WT mice $2 \mathrm{~h}$ after trauma $(48,49)$. These values are comparable to the relative reduction in blood flow observed at $2 \mathrm{~h}$ after CCI in our present study. CBF changes detected by LDF were only consistently significant in the peri-contusional areas of the brain (e.g., penumbra), which are vulnerable to additional secondary insults (e.g., hypoxia, hypotension). Importantly, these same areas are often considered as potentially salvable cerebral tissue that could contribute in the recovery and outcome after TBI.

Discovery of Epo and EpoR in many non-erythroid organs and tissues such as endothelial cells, reproductive organs, heart, gastrointestinal tract, muscle cells, and the central nervous system (CNS) suggests a wide variety of actions $(23,50,51)$. Different cell types (neurons, glia and endothelial cells) in the nervous system produce Epo and express EpoR, and Epo appears to have 
multiple actions in the nervous system. Epo has neuroprotective effects after ischemic, hypoxic, metabolic, neurotoxic, and excitotoxic stress in the nervous system. This neuroprotection potentially operates simultaneously at several levels in the central nervous system, such as limiting the production of reactive oxygen species and glutamate, neurotransmission modulation, reversal of vasospasm, promoting angiogenesis, preventing apoptosis, reduction of inflammation, and stem cell recruitment. Our study indicates that some of the neuroprotective effect results from maintenance of CBF by an eNOS dependent mechanism. Similarly, NOS dependency of the neuroprotective effects of Epo has been described in the restoration of working memory deficits in rats subjected to global transient ischemia (52). Interestingly, in the stable tubule only polypeptide (STOP) null mouse model that displays neurochemical and behavioral aspects of schizophrenia, Epo results in an improvement in cognitive function that is NO dependent. These studies of working memory restoration in transient global ischemia and cognitive function in STOP mice used pharmacological inhibition of NOS, so it is not possible to discern if the effects were mediated by eNOS or nNOS.

Studies of the effects of Epo in organs other than the brain as well as in vitro endothelial cells suggest that protective effects are eNOS dependent. In cultured lung endothelial cells, hypoxia leads to constriction but in the presence of Epo there is up-regulation of eNOS with increased NO production leading to vasorelaxation. In addition, the NO leads to up-regulation of EpoR in these cells suggesting a coordinated response of these signaling molecules (53). In studies of sepsis in which tumor necrosis factor induces microvascular inflammation in striated muscle, Epo ameliorates the microvascular damage by an eNOS dependent mechanism but the protective effect is independent of iNOS (54). Similarly, Epo prevents sepsis-related acute kidney in rats by up-regulating eNOS (55). In ischemic musculocutaneous skin flaps, Epo administration up-regulates eNOS and the protective effect is abrogated by administration of eNOS inhibitors (56). Administration of Epo has also been shown to reduce the depth and area of secondary burn progression (57). These extra-hematopoietic eNOS dependent protective actions may result, at least in part, from vasodilation with increased blood flow.

The purpose of the present study is to identify the effect of Epo on CBF changes measured by LDF after TBI and the dependence of these changes on eNOS. Binding of Epo to its receptor (EpoR) on the endothelial cells of the cerebral vasculature leads to phosphorylation of JAK-2 that activates the PI3-K/AKT pathway resulting in eNOS activation by phosphorylation. The increased activity of eNOS increases NO production resulting in cerebral vasodilation and increased CBF. Epo administration resulted in significantly higher LDF in the peri-contusional sites only in the WT mice and eNOS-deficient mice showed poorer LDF recovery after injury in the peri-contusional sites with both treatment groups (Epo vs. saline; $p>0.05$ ) having comparable LDF values at $120 \mathrm{~min}$ after CCI. The relatively rapid increase in CBF following Epo administration after CCI is likely due to direct signaling pathways in the cerebral vasculature leading to eNOS activation and NO production rather than other slower Epo effects that depend on transcriptional regulation. The rapid time course of changes in $\mathrm{CBF}$ also indicates direct physiological effect rather than impaired vascular remodeling in the eNOS-deficient animals or up-regulation of inducible or neuronal NOS. Previous studies have shown that restoration of penumbral blood flow using NO augmentation is associated with better behavioral, histological, and contusion volume outcome following CCI. A recent study using inhaled NO in the CCI suggests that CBF can be restored without disrupting cerebral autoregulation, increasing intracranial pressure, or protein nitrosylation, and that augmenting NO by this means results in reduced contusion volume and better behavioral outcome (58).

There are some technical limitations of this study. CBF was measured using laser Doppler which provides arbitrary PUs rather than quantitative CBF that can be expressed in $\mathrm{ml} / \mathrm{mg} / \mathrm{min}$; therefore, we measured relative perfusion. The major advantage of using laser Doppler is that this technique enables rapid serial measurements. Lundband et al. measured cortical blood flow following CCI in eNOS-deficient mice using [14C]-iodoantipyrine at 3 and $24 \mathrm{~h}$ after injury (49). The magnitude of CBF change they observed at $3 \mathrm{~h}$ was similar to that we observed at $30 \mathrm{~min}, 1 \mathrm{~h}$ and $2 \mathrm{~h}$ after injury.

Our study supports the importance of eNOS and NO in the very early stages in the pathophysiology of TBI in maintaining adequate $\mathrm{CBF}$ as well as the positive effect of Epo in re-establishing the CBF in the penumbra within $2 \mathrm{~h}$ after the injury by a NO dependent mechanism. These findings support the potential for very early administration of Epo or Epo agonists in the management of TBI.

\section{ACKNOWLEDGMENTS}

Sources of Support: NIH NINDS P01-NS38660.

\section{REFERENCES}

1. Coronado VG, Xu L, Basavaraju SV, McGuire LC, Wald MM, Faul MD, et al. Surveillance for traumatic brain injury-related deaths - United States, 1997-2007. MMWR Surveill Summ (2011) 60(5):1-32.

2. Narayan RK, Michel ME, Ansell B, Baethmann A, Biegon A, Bracken MB, et al. Clinical trials in head injury. J Neurotrauma (2002) 19:503-57. doi:10.1089/ 089771502753754037

3. Celik M, Gökmen N, Erbayraktar S, Akhisaroglu M, Konakc S, Ulukus C, et al. Erythropoietin prevents motor neuron apoptosis and neurologic disability in experimental spinal cord ischemic injury. Proc Natl Acad Sci U S A (2002) 99:2258-63. doi:10.1073/pnas.042693799

4. Gorio A, Gokmen N, Erbayraktar S, Yilmaz O, Madaschi L, Cichetti C, et al. Recombinant human erythropoietin counteracts secondary injury and markedly enhances neurological recovery from experimental spinal cord trauma. Proc Natl Acad Sci U S A (2002) 99:9450-5. doi:10.1073/pnas.142287899

5. Minnerup J, Heidrich J, Rogalewski A, Schabitz WR, Wellmann J. The efficacy of erythropoietin and its analogues in animal stroke models: a meta-analysis. Stroke (2009) 40:3113-20. doi:10.1161/STROKEAHA.109.555789

6. Catania MA, Marciano MC, Parisi A, Sturiale A, Buemi M, Grasso G, et al. Erythropoietin prevents cognition impairment induced by transient brain ischemia in gerbils. Eur J Pharmacol (2002) 437:147-50. doi:10.1016/S0014-2999(02) 01292-X

7. Junk AK, Mammis A, Savitz SI, Singh M, Roth S, Malhotra S, et al. Erythropoietin administration protects retinal neurons from acute ischemia-reperfusion injury. Proc Natl Acad Sci U S A (2002) 99:10659-64. doi:10.1073/pnas. 152321399

8. Murphy AM, Xenocostas A, Pakkiri P, Lee TY. Hemodynamic effects of recombinant human erythropoietin on the central nervous system after subarachnoid hemorrhage: reduction of microcirculatory impairment and functional deficits in a rabbit model. J Neurosurg (2008) 109:1155-64. doi:10.3171/JNS.2008.109. 12.1155

9. Rahimi NedjatM, Wähmann M, Bächli H, Güresir E, Vatter H, Raabe A, et al. Erythropoietin neuroprotection is enhanced by direct cortical application following 
subdural blood evacuation in a rat model of acute subdural hematoma. Neuroscience (2013) 238:125-34. doi:10.1016/j.neuroscience.2013.01.067

10. Yatsiv I, Grigoriadis N, Simeonidou C, Stahel PF, Schmidt OI, Alexandrovitch AG, et al. Erythropoietin is neuroprotective, improves functional recovery, and reduces neuronal apoptosis and inflammation in a rodent model of experimental closed head injury. FASEB J (2005) 19(12):1701-3.

11. Chen G, Shi JX, Hang CH, Xie W, Liu J, Liu X. Inhibitory effect on cerebral inflammatory agents that accompany traumatic brain injury in a rat model: a potential neuroprotective mechanism of recombinant human erythropoietin (rhEPO). Neurosci Lett (2007) 425:177-82. doi:10.1016/j.neulet.2007.08.022

12. Ozturk E, Demirbilek S, Kadir But A, Saricicek V, Gulec M, Akyol O, et al. Antioxidant properties of propofol and erythropoietin after closed head injury in rats. Prog Neuropsychopharmacol Biol Psychiatry (2005) 29:922-7. doi:10. 1016/j.pnpbp.2005.04.028

13. Mahmood A, Lu D, Qu C, Goussev A, Zhang ZG, Lu C, et al. Treatment of traumatic brain injury in rats with erythropoietin and carbamylated erythropoietin. J Neurosurg (2007) 107:392-7. doi:10.3171/JNS-07/08/0392

14. Grasso G, Sfacteria A, Meli F, Fodale V, Buemi M, Iacopino DG. Neuroprotection by erythropoietin administration after experimental traumatic brain injury. Brain Res (2007) 1182:99-105. doi:10.1016/j.brainres.2007.08.078

15. Liao ZB, Zhi XG, Shi QH, He ZH. Recombinant human erythropoietin administration protects cortical neurons from traumatic brain injury in rats. Eur J Neurol (2008) 15:140-9. doi:10.1111/j.1468-1331.2007.02013.x

16. Liao ZB, Jiang GY, Tang ZH, Zhi XG, Sun XC, Tang WY, et al. Erythropoietin can promote survival of cerebral cells by downregulating Bax gene after traumatic brain injury in rats. Neurol India (2009) 57:722-8. doi:10.4103/00283886.59466

17. Cherian L, Goodman JC, Robertson C. Neuroprotection with erythropoietin administration following controlled cortical impact injury in rats. J Pharmacol Exp Ther (2007) 322:789-94. doi:10.1124/jpet.107.119628

18. Cherian L, Goodman JC, Robertson C. Improved cerebrovascular function and reduced histological damage with darbepoetin alfa administration after cortical impact injury in rats. J Pharmacol Exp Ther (2011) 337:451-6. doi:10.1124/jpet. 110.176602

19. Robertson CS, Cherian L, Shah M, Garcia R, Navarro JC, Grill RJ, et al. Neuroprotection with an erythropoietin mimetic peptide (pHBSP) in a model of mild traumatic brain injury complicated by hemorrhagic shock. J Neurotrauma (2012) 29:1156-66. doi:10.1089/neu.2011.1827

20. Bouzat P, Millet A, Boue Y, Pernet-Gallay K, Trouve-Buisson T, GaideChevronnay L, et al. Changes in brain tissue oxygenation after treatment of diffuse traumatic brain injury by erythropoietin. Crit Care Med (2013) 41:1316-24. doi:10.1097/CCM.0b013e31827ca64e

21. Kretz A, Happold CJ, Marticke JK, Isenmann S. Erythropoietin promotes regeneration of adult CNS neurons via Jak2/Stat 3 and PI3K/AKT pathway activation. Mol Cell Neurosci (2005) 29:569-79. doi:10.1016/j.mcn.2005.04.009

22. Lin FK, Suggs S, Lin CH, Browne JK, Smalling R, Egrie JC, et al. Cloning and expression of the human erythropoietin gene. Proc Natl Acad Sci U S A (1985) 82:7580-4. doi:10.1073/pnas.82.22.7580

23. Zhang Y, Wang L, Dey S, Alnaeeli M, Suresh S, Rogers H, et al. Erythropoietin action in stress response, tissue maintenance and metabolism. Int J Mol Sci (2014) 15:10296-333. doi:10.3390/ijms150610296

24. Jones NM, Bergeron M. Hypoxic preconditioning induces changes in HIF-1 target genes in neonatal rat brain. J Cereb Blood Flow Metab (2001) 21:1105-14. doi:10.1097/00004647-200109000-00008

25. Sharp FR, Ran R, Lu A, Tang Y, Strauss KI, Glass T, et al. Hypoxic preconditioning protects against ischemic brain injury. NeuroRx (2004) 1(1):26-35. doi:10.1602/neurorx.1.1.26

26. Marzo F, Lavorgna A, Coluzzi G, Santucci E, Tarantino F, Rio T, et al. Erythropoietin in heart and vessels: focus on transcription and signalling pathways. J Thromb Thrombolysis (2008) 26:183-7. doi:10.1007/s11239-008-0212-3

27. Brines M, Cerami A. Discovering erythropoietin's extra-hematopoietic functions: biology and clinical promise. Kidney Int (2006) 70:246-50. doi:10.1038/ sj.ki.5001546

28. Chavez JC, LaManna JC. Activation of hypoxia-inducible factor-1 in the rat cerebral cortex after transient global ischemia: potential role of insulin-like growth factor-1. J Neurosci (2002) 22(20):8922-31.

29. Semenza GL. Hydroxylation of HIF-1: oxygen sensing at the molecular level. Physiology (Bethesda) (2004) 19:176-82. doi:10.1152/physiol.00001.2004
30. Semenza GL. Hypoxia-inducible factors in physiology and medicine. Cell (2012) 148:399-408. doi:10.1016/j.cell.2012.01.021

31. Xu Y, Tian Y, Wei HJ, Chen J, Dong JF, Zacharek A, et al. Erythropoietin increases circulating endothelial progenitor cells and reduces the formation and progression of cerebral aneurysm in rats. Neuroscience (2011) 181:292-9. doi:10.1016/j.neuroscience.2011.02.051

32. Teng R, Calvert JW, Sibmooh N, Piknova B, Suzuki N, Sun J, et al. Acute erythropoietin cardioprotection is mediated by endothelial response. Basic Res Cardiol (2011) 106:343-54. doi:10.1007/s00395-011-0158-z

33. Gao E, Boucher M, Chuprun JK, Zhou RH, Eckhart AD, Koch WJ. Darbepoetin alfa, a long-acting erythropoietin analog, offers novel and delayed cardioprotection for the ischemic heart. Am J Physiol Heart Circ Physiol (2007) 293:H60-8. doi:10.1152/ajpheart.00227.2007

34. Cherian L, Chacko G, Goodman JC, Robertson CS. Cerebral hemodynamic effects of phenylephrine and L-arginine after cortical impact injury. Crit Care Med (1999) 27:2512-7. doi:10.1097/00003246-199911000-00031

35. Lee ST, Chu K, Sinn DI, Jung KH, Kim EH, Kim SJ, et al. Erythropoietin reduces perihematomal inflammation and cell death with eNOS and STAT3 activations in experimental intracerebral hemorrhage. J Neurochem (2006) 96:1728-39. doi:10.1111/j.1471-4159.2006.03697.x

36. Hellewell SC, Yan EB, Alwis DS, Bye N, Morganti-Kossmann MC. Erythropoietin improves motor and cognitive deficit, axonal pathology, and neuroinflammation in a combined model of diffuse traumatic brain injury and hypoxia, in association with upregulation of the erythropoietin receptor. J Neuroinflammation (2013) 10:156. doi:10.1186/1742-2094-10-156

37. LASSEN NA. Cerebral blood flow and oxygen consumption in man. Physiol Rev (1959) 39:183-238.

38. Gross SS, Wolin MS. Nitric oxide: pathophysiological mechanisms. Annu Rev Physiol (1995) 57:737-69. doi:10.1146/annurev.ph.57.030195.003513

39. Clark RS, Kochanek PM, Schwarz MA, Schiding JK, Turner DS, Chen M, et al. Inducible nitric oxide synthase expression in cerebrovascular smooth muscle and neutrophils after traumatic brain injury in immature rats. Pediatr Res (1996) 39:784-90. doi:10.1203/00006450-199605000-00007

40. Rangel-Castilla L, Ahmed O, Goodman JC, Gopinath S, Valadka A, Robertson C. L-Arginine reactivity in cerebral vessels after severe traumatic brain injury. Neurol Res (2010) 32:1033-40. doi:10.1179/016164110X12767786356598

41. Robertson CS, Gopinath SP, Valadka AB, Van M, Swank PR, Goodman JC. Variants of the endothelial nitric oxide gene and cerebral blood flow after severe traumatic brain injury. J Neurotrauma (2011) 28:727-37. doi:10.1089/ neu. 2010.1476

42. Jafarian-Tehrani M, Louin G, Royo NC, Besson VC, Bohme GA, Plotkine M, et al. $1400 \mathrm{~W}$, a potent selective inducible NOS inhibitor, improves histopathological outcome following traumatic brain injury in rats. Nitric Oxide (2005) 12:61-9. doi:10.1016/j.niox.2004.12.001

43. Louin G, Marchand-Verrecchia C, Palmier B, Plotkine M, Jafarian-Tehrani M. Selective inhibition of inducible nitric oxide synthase reduces neurological deficit but not cerebral edema following traumatic brain injury. Neuropharmacology (2006) 50:182-90. doi:10.1016/j.neuropharm.2005.08.020

44. Lu J, Moochhala S, Shirhan M, Ng KC, Teo AL, Tan MH, et al. Neuroprotection by aminoguanidine after lateral fluid-percussive brain injury in rats: a combined magnetic resonance imaging, histopathologic and functional study. Neuropharmacology (2003) 44:253-63. doi:10.1016/S0028-3908(02)00380-5

45. Prough DS, Kramer GC, Uchida T, Stephenson RT, Hellmich HL, Dewitt DS. Effects of hypertonic arginine on cerebral blood flow and intracranial pressure after traumatic brain injury combined with hemorrhagic hypotension. Shock (2006) 26:290-5. doi:10.1097/01.shk.0000225405.66693.49

46. Marion DW, Darby J, Yonas H. Acute regional cerebral blood flow changes caused by severe head injuries. J Neurosurg (1991) 74:407-14. doi:10.3171/jns.1991.74. 3.0407

47. Shesely EG, Maeda N, Kim HS, Desai KM, Krege JH, Laubach VE, et al. Elevated blood pressures in mice lacking endothelial nitric oxide synthase. Proc Natl Acad Sci U S A (1996) 93:13176-81. doi:10.1073/pnas.93.23.13176

48. Hlatky R, Goodman JC, Valadka AB, Robertson CS. Role of nitric oxide in cerebral blood flow abnormalities after traumatic brain injury. J Cereb Blood Flow Metab (2003) 23:582-8. doi:10.1097/01.WCB.0000059586.71206.F3

49. Lundblad C, Grande PO, Bentzer P. Hemodynamic and histological effects of traumatic brain injury in eNOS-deficient mice. J Neurotrauma (2009) 26:1953-62. doi:10.1089/neu.2009.0955 
50. Feldman L, Sytkowski AJ. Pleiotrophic actions of erythropoietin. Environ Health Prev Med (2003) 7:239-45. doi:10.1007/BF02908882

51. Sytkowski AJ. The neurobiology of erythropoietin. Cell Mol Neurobiol (2011) 31:931-7. doi:10.1007/s10571-011-9695-0

52. Samson ML, Kajitani K, Robertson GS. Nitric-oxide synthase mediates the ability of darbepoetin alfa to attenuate pre-existing spatial working memory deficits in rats subjected to transient global ischemia. J Pharmacol Exp Ther (2010) 333:437-44. doi:10.1124/jpet.110.165530

53. Beleslin-Cokic BB, Cokic VP, Wang L, Piknova B, Teng R, Schechter AN, et al. Erythropoietin and hypoxia increase erythropoietin receptor and nitric oxide levels in lung microvascular endothelial cells. Cytokine (2011) 54:129-35. doi:10.1016/j.cyto.2011.01.015

54. Contaldo C, Lindenblatt N, Elsherbiny A, Högger DC, Borozadi MK, Vetter ST, et al. Erythropoietin requires endothelial nitric oxide synthase to counteract TNF-[alpha]-induced microcirculatory dysfunction in murine striated muscle. Shock (2011) 35:315-21. doi:10.1097/SHK.0b013e3181fd0700

55. Souza AC, Volpini RA, Shimizu MH, Sanches TR, Camara NO, Semedo P, et al. Erythropoietin prevents sepsis-related acute kidney injury in rats by inhibiting NF-kappaB and upregulating endothelial nitric oxide synthase. Am J Physiol Renal Physiol (2012) 302:F1045-54. doi:10.1152/ajprenal.00148.2011

56. Rezaeian F, Wettstein R, Egger JF, Sandmann F, Rücker M, Tobalem M, et al. Erythropoietin-induced upregulation of endothelial nitric oxide synthase but not vascular endothelial growth factor prevents musculocutaneous tissue from ischemic damage. Lab Invest (2010) 90:40-51. doi:10.1038/labinvest. 2009.117
57. Tobalem M, Harder Y, Rezaeian F, Wettstein R. Secondary burn progression decreased by erythropoietin. Crit Care Med (2013) 41:963-71. doi:10.1097/ CCM.0b013e318275cee7

58. Terpolilli NA, Kim SW, Thal SC, Kuebler WM, Plesnila N. Inhaled nitric oxide reduces secondary brain damage after traumatic brain injury in mice. J Cereb Blood Flow Metab (2013) 33:311-8. doi:10.1038/jcbfm.2012.176

Conflict of Interest Statement: The authors declare that the research was conducted in the absence of any commercial or financial relationships that could be construed as a potential conflict of interest.

Received: 28 July 2014; accepted: 23 September 2014; published online: 09 October 2014.

Citation: Cruz Navarro J, Pillai S, Ponce LL, Van M, Goodman JC and Robertson CS (2014) Endothelial nitric oxide synthase mediates the cerebrovascular effects of erythropoietin in traumatic brain injury. Front. Immunol. 5:494. doi: 10.3389/fimmu.2014.00494

This article was submitted to Inflammation, a section of the journal Frontiers in Immunology.

Copyright (c) 2014 Cruz Navarro, Pillai, Ponce, Van, Goodman and Robertson. This is an open-access article distributed under the terms of the Creative Commons Attribution License (CC BY). The use, distribution or reproduction in other forums is permitted, provided the original author(s) or licensor are credited and that the original publication in this journal is cited, in accordance with accepted academic practice. No use, distribution or reproduction is permitted which does not comply with these terms. 